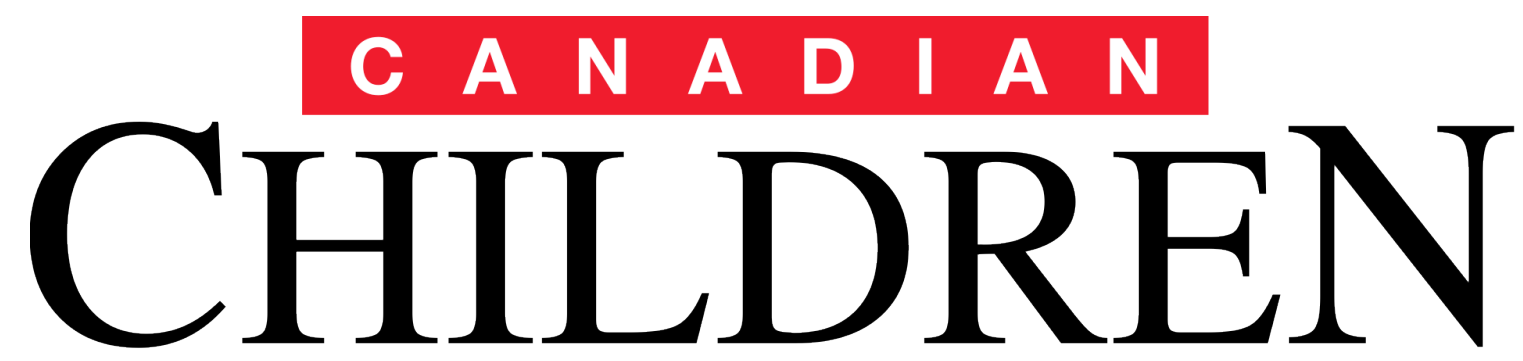

JOURNAL OF THE CANADIAN ASSOCIATION FOR YOUNG CHILDREN

Winter 2015/Hiver 2015

Vol. 40 No. 1

\title{
The Glass Ceiling Effect: Mediating Influences on Early Years' Educators Sense of Professionalism
} By Stephanie Tukonic and Debra Harwood

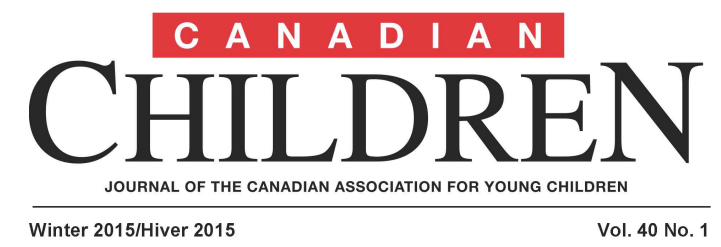

Editors:

Dr. Laurie Kocher, Douglas College, Coquitlam, British Columbia Dr. Veronica Pacini-Ketchabaw, University of Victoria, Victoria, British Columbia

Guest Editors, Special Issue: Professionalism in ECEC Dr. Rachel Langford, Dr. Jane Hewes, Sonya Hooper, and

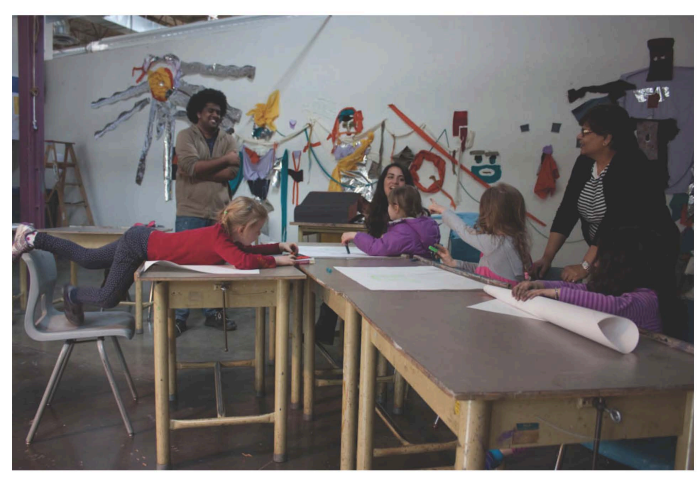
Monica Lysack

Publications Chairperson:

Dr. Iris Berger, University of British Columbia, Vancouver, British Columbia

Cover Photo:

Dr. Sylvia Kind

(c) 1996: The Canadian Association for Young Children ISSN: 0833-7519

Author Guidelines: visit www.cayc.ca

Published with support from the Social Sciences and Humanities Research Council of Canada

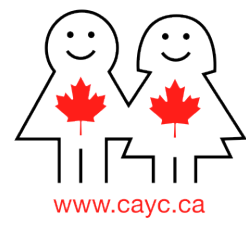




\title{
Canadian Children
}

\section{JOURNAL OF THE CANADIAN ASSOCIATION FOR YOUNG CHILDREN}

Volume 40 Number 12015 [page 36 to 54]

www.cayc.ca

\section{The Glass Ceiling Effect: Mediating Influences on Early Years Educators' Sense of Professionalism}

\section{by Stephanie Tukonic and Debra Harwood}

\begin{abstract}
Authors' Bios
Stephanie Tukonic is a graduate of the master's program of Brock University. She is a research intern for Children's Services, Community Services of Niagara Region, Ontario. Email: Stephanie.Tukonic@niagararegion.ca

Debra Harwood is an associate professor at Brock University. She co-developed and teaches within the Bachelor of Early Childhood Education degree program and focuses her research interests on professionalism, and curriculum and pedagogy in the early years. Email: dharwood@brocku.ca
\end{abstract}

\begin{abstract}
The Ontario landscape of early years education is undergoing dramatic shifts, perhaps a sign of a beginning movement toward an integrated publicly funded delivery system model. Ontario is engaged in the final phase of a 5-year implementation plan to incorporate services for 4- and 5-year-olds within the educational sector. The full-day early learning-kindergarten program (ELKP) is a model that relies on the collaboration and professionalism of a teacher and an early childhood educator within each ELKP classroom. While early childhood education programs for children 0-4 years of age continue to be provided via a marketdelivery system, the legislative and regulatory framework for child care now resides with the Ministry of Education. Potentially, merging these two distinct fields (care and education) within one ministry can provoke ideological discussions related to professionalism, a facet that is noticeably absent in the policy and framework literature produced by the Ministry thus far. As teachers and early childhood educators collaborate within ELKP classrooms and beyond, ideologies and praxis encounters can challenge one's sense of professionalism. Thirty-seven early years
\end{abstract}


educators participated in a study examining concepts of professionalism and the factors that mediate and influence professional identity. The findings indicate that educators perceive a "glass ceiling" effect in their profession. Perhaps a reimagining of the glass ceiling can be fostered by finding ways to challenge policy makers and educational systems to consider both new models of training/education and pathways for the co-construction of professional identities for teachers and educators.

\section{A Shifting Landscape of Care and Education}

Over the last decade, a call for greater integration and alignment of policy between early childhood care and education (ECCE) and schooling has emerged, both internationally and in Canada. Pointedly, the Organisation for Economic Cooperation and Development (OECD) emphasizes the need for a "systemic and integrated approach to early childhood care and education policy and a strong and equal partnership with the education system" (Organisation for Economic Cooperation and Development, 2006, p. 3 ) as two of eight key elements of successful ECCE policy. Furthermore, in the first Starting Strong report (Organisation for Economic Cooperation and Development, 2001), several suggestions were highlighted to foster systems integration and address the historical issue of the two-tiered system of care (for children from birth to 3 years) and education (for children 3 years old and older) that developed in many of the OECD member countries, including Canada. ${ }^{\mathrm{i}}$ The OECD (2001) recommends strong links across services, professionals, and parents in each community and the promotion of "equality of relationship and strong continuity between early childhood provision and the education system" (p. 58). How this partnership and equality between the two sectors are operationalized, however, raises some interesting questions. For example, which sector will dominate? How does equality of relationships impact professionalism and professional identity construction? Within Canada, much of the discourse on systems integration focuses on early education serving as a precursor to, and in support of the objectives of, public education; a clear 'readiness for school' orientation appears to dominate much of the dialogue (Moss, 2013). Moss discusses some of the potential inherent dangers in the development of a relationship between early childhood education and compulsory schooling within a model that has been historically a "split delivery" system (e.g., Canada, United States, Australia, United Kingdom).

The sectors typically differ in important respects: administration, regulation, curriculum, access, funding, workforce, and types of provision. This is not a case of different but equal, but different and unequal. (Moss, 2013, p. 7)

Ontario provides one context within Canada to examine the movement toward a publicly funded integrated systems model. The Ontario landscape of early years education is undergoing dramatic shifts. The province is currently engaged in the final 
phase of a 5-year implementation plan to incorporate services for 4- and 5-year-olds within the educational sector. The full-day early learning-kindergarten program (ELKP) is a model that relies on the collaboration and professionalism of a teacher and an early childhood educator within each ELKP classroom. And, although early childhood education (ECE) programs for children 0-3 years of age continue to be provided via a market-delivery system, the legislative and regulatory framework for child care now resides with the Ministry of Education. The Ministry's 2010-11 draft report on the new program noted that the ELKP team "will have the benefit of a collaborative and complementary partnership to support children and families in a high-quality, intentional, play-based learning environment" (Ontario Ministry of Education, 2010, p. 8). Teachers are responsible for the long-term planning and organization of the program and the management of these classes, while early childhood educators are responsible for ageappropriate program planning that facilitates experiences that promote physical, emotional, social, language, and cognitive child development (Ontario Ministry of Education, 2010). Potentially, merging these historically distinct professions might provoke ideological and praxis encounters that could challenge educators' and teachers' sense of professionalism. If Ontario is to achieve the aims of the OECD Starting Strong reports $(2001,2006)$, "equality of relationship and strong continuity between early childhood provision and the education system" (Organisation for Economic Cooperation and Development, 2001, p. 58) must be realized at both the macro (e.g., attitudes and ideologies of the culture) and micro (e.g., school, peers, and family) levels.

This small-scale study of 37 early years educators in Ontario examined the educators' concepts of professionalism and the factors that mediate and influence professional identity. Initially the study aimed to include both kindergarten teachers and early childhood educators. However, the majority of the self-nominated participants were registered early childhood educators (RECEs); few teachers completed the survey. Thus, throughout this article we utilize the terms "educator" and "early years sector" to refer to all the participants of the study who held positions within the educational field at the time the data were collected (including preschools, child care and education centres, and halfday and ELKP kindergarten programs). Our interest in this study rested with understanding how early years educators defined their own sense of professionalism, and the ways in which professional perceptions may be impacted by one's role (i.e., as a teacher or RECE). Additionally, the data collection took place during year 2 of the implementation of the ELKP model, thus we sought ways to explore how the merging of two sectors and the changing landscape of early years education in Ontario provided opportunities and/or challenges to professional identity construction.

The findings indicate that a "glass ceiling" effect was perceived by early childhood educators that acted to limit and constrain their insights of professional identity. In this article, we borrow the metaphor of the glass ceiling from Cotter, Hermsen, Ovadia, and Vanneman (2001) to explore some of the barriers and inequalities 
that may potentially impact and limit early childhood educators' sense of professionalism. And, although Cotter and his colleagues use the term "glass ceiling" to refer strictly to gender and race inequalities, in this article we utilize the concept more liberally to explore some of the structural and attitudinal barriers that may exist in the current Ontario early years sector. For example, the educators who participated in this study identified pay and education level differences between early childhood educators and teachers, lack of administration leadership, and societal misunderstandings as some of these barriers. We highlight the study's preliminary findings in the hope of challenging policy makers and educational systems to consider both new models of training/education and pathways for the co-construction of professional identities for teachers and early childhood educators alike. Potentially, by reimagining the glass ceiling, new opportunities and pathways to educator professionalism can be realized.

\section{Defining Professionalism}

In the Canadian ECE context, the concept of professionalism is a relatively new discussion. Amid long-held public conceptions of early childhood educators as mere care providers or babysitters; early childhood educators themselves have been reluctant to enter the debate on professionalism (Brock, 2012). Moreover, little agreement exists within the literature in defining the construct, adding to the challenge of researching educators' conceptions of professionalism (Martin, Meyer, Jones, Nelson, \& Ling, 2010). According to the Oxford online dictionary, a professional is an individual who demonstrates proficiency and skill within a particular profession (Oxford University Press, 2014). This somewhat simplistic definition adds little to understanding the complexity of what constitutes a profession and a professional. In 1985 Lilian Katz utilized what she deemed "scientific conceptions" in a discussion of educator professionalism, naming eight criteria that need to be met for the term professional(ism) to apply: social necessity, altruism, autonomy, code of ethics, distance from client, standards of practice, prolonged training, and specialized knowledge (Katz, 1985). In 2001, Cherrington (cited in Dalli, 2008) added to the discussion by highlighting four cornerstones of professionalism, namely, "professionalism of interpersonal actions, having and acting upon a professional knowledge base, acting in the child's best interest, and taking professional responsibility for the actions of one's colleagues" (p. 174). Contemporary conceptualizations emphasize "early childhood professionalism [as] something whose meaning appears to be embedded in local contexts, visible in relational interactions, ethical and political in nature, and involving multiple layers of knowledge, judgement, and influences from the broader societal context" (Dalli, Miller, \& Urban, 2012 , p. 6). Thus, professionalism appears to be a "multi-layered and multi-faceted concept" (Miller \& Cable, 2011, p. 8) whose definition requires a "ground-up" perspective from educators themselves (Dalli, 2008; Martin et al., 2010).

\section{Canadian Children}


In the thirty years since Katz's original discussion, the ECE field has made advances in the eight criteria she outlined. For some countries (e.g., New Zealand), the discussion of professionalism has moved well beyond whether or not an educator is a professional to focus more on the quality and continuity of professional learning and the development of all educators (Cherrington \& Thornton, 2013). Dalli (1993) and others (Lee, 2012; Opper, 1993) argue that the ECE field has made significant gains that challenge its historical "Cinderella" status of being "undervalued and underfunded" (Dalli, p. 3). This ability to challenge historical notions of what constitutes a professional educator seems particularly important since, as Hargreaves (2000) describes in a discussion related to teachers, a sense of professionalism has to do with "how teachers feel they are seen through other people's eyes - in terms of their status, standing, regard and levels of professional reward" (p. 152). And, although Ontario has made strides in prioritizing early years education, we argue that the Cinderella syndrome is still pervasive within this context. Comparable to other locales, the Canadian discourse on professionalism and the early childhood educator is relatively underdeveloped, with educators' voices largely silent (Brock, 2012).

\section{The Research Methodology}

The study employed a web-based questionnaire that explored concepts of professionalism and professional identities of educators and teachers in the ECE sector. The study aimed to include all early years educators (i.e., both kindergarten teachers and early childhood educators). Thus, educators and teachers were invited to participate in the study through various early years associations and professional networks. However, only five teachers responded to the survey and identified themselves as kindergarten teachers; therefore, comparative measures of differences in perceptions of professionalism Between early childhood educators and teachers were not possible within the scope of this study. Consequently, throughout the description of methods and findings, we utilize the terms "educator" and "early years sector" to refer to all of the study participants.

The design of the questionnaire was informed by previous research related to educator professionalism (Dalli, 2008; Martin et al., 2010; Rodgers \& Raider-Roth, 2006) and by adapting the Profile of Child Care Professionals measure (Martin et al., 2010). Additionally, specific factors that contribute to feelings of being a professional were also explored (e.g., commitment to the field of specialization, education, expert knowledge, pedagogy, and ethics).

The first section, the quantitative portion of the questionnaire, asked participants to share their perceptions and beliefs related to the ethics, practice, care, and knowledge incumbent on an early years educator. The educators' perceptions and beliefs were collectively compared with the varied participant characteristics (e.g., years of experience, role, and level of education). The second section, the qualitative aspect of the 
questionnaire, explored what participants perceived the qualities of a professional early years educator to be and any challenges they associated in the construction of professional identity.

Both quantitative and qualitative data were analyzed. The quantitative data were analyzed using a statistical software program, SPSS 20.0, to perform descriptive analysis and limited inferential statistical examination. Descriptive statistics were calculated for the frequency of each response and the mean response of each question. In addition, several nonparametric tests of analysis were conducted to collectively compare the perceptions of professionalism of early childhood educators with several participant characteristics. The qualitative data analysis was supported with the use of NVivo 9 to generate theme-based frequencies that emerged in the coding process. These codes were assigned to participant responses that were then used to form descriptions and broader themes in the data set (Creswell, 2012). Two overarching meta-themes emerged from the study: educators' self-perceptions of professionalism, and mediating influences on professional identity. Potentially, these mediating influences can create a glass ceiling effect for professionalism and educator professional identity construction.

\section{The Participating Educators}

Thirty-seven early years educators participated in the study. The participant profiles (i.e., gender, years of experience, family income, education level, and role) are detailed in Table 1.

Table 1. Profile of participant characteristics.

\begin{tabular}{|c|c|c|}
\hline $\begin{array}{c}\text { Participant } \\
\text { Profile }\end{array}$ & Characteristics & Percentage of Responses \\
\hline \multirow{2}{*}{ Gender } & Female & 100.0 \\
\hline \multirow{4}{*}{$\begin{array}{c}\text { Years of } \\
\text { Experience }\end{array}$} & Less than 5 years & 10.8 \\
\cline { 2 - 3 } & 6 to 10 years & 10.8 \\
\cline { 2 - 3 } & 11 to 15 years & 16.2 \\
\cline { 2 - 3 } & More than 21 years & 29.7 \\
\hline \multirow{3}{*}{ Education Level } & College Diploma (2 years) & 62.2 \\
\cline { 2 - 3 } & University Degree Completed & 10.8 \\
\hline
\end{tabular}




\begin{tabular}{|c|c|c|}
\hline & (includes Bachelor of Education) & \\
\hline & $\begin{array}{l}\text { University Degree Completed } \\
\text { (not including Bachelor of } \\
\text { Education) }\end{array}$ & 13.5 \\
\hline & Master's Degree & 13.5 \\
\hline \multirow{4}{*}{ Role } & Early Childhood Educator (RECE) & 40.5 \\
\hline & Director/Manager ECE & 27.0 \\
\hline & Other ECE Role & 18.9 \\
\hline & $\begin{array}{c}\text { Junior Kindergarten / } \\
\text { Senior Kindergarten Teacher } \\
\text { (certified teacher) }\end{array}$ & 13.5 \\
\hline
\end{tabular}

The participants, all female, tended to be proficient or experts in their field (Katz, 1972). In descending order of frequency, the participants indicated their role as the following: a registered early childhood educator (RECE), director/manager ECE, other ECE role, or junior kindergarten / senior kindergarten teacher (certified teacher). Aligned with the practices of teachers and the mandate of the Ontario College of Teachers (2013), the practice of early childhood education in Ontario is regulated by the College of Early Childhood Educators in accordance with the Early Childhood Educators Act, 2007 (College of Early Childhood Educators, 2013). Thus, the term RECE refers to an individual who is registered with the College and accountable to act in accordance with its regulations. The 5 participating teachers and 32 educators were all registered members of their respective Colleges. In addition, many participants (27\%) reported that they currently held a position as a director or manager of an early childhood centre. In Ontario, the director of a centre often maintains responsibility for administrative and leadership duties and they often also uphold educator responsibilities in programming and interacting with children. The majority of the respondents $(62.2 \%)$ held a two-year diploma, which adheres to the province's minimal qualification expectation for early childhood educators (Government of Ontario, 1990).

\section{Quantified Perceptions of Professionalism}

The quantitative section of the questionnaire captured and examined perceptions and beliefs related to the ethics, practice, care, and knowledge incumbent on an early years educator. All educators $(100 \%)$ considered themselves to be professional. The 
majority of the educators (93.5\%) reported that they felt qualified and confident to help others learn about the role of an early years educator, with $90.6 \%$ stating that they had a clear understanding of the roles and responsibilities of their current position. Moreover, approximately half $(46.9 \%)$ of the educators agreed strongly with the statement that they felt supported in their role. Approximately one-third of the educators (38.7\%) felt strongly that others demonstrated respect for their current position. Almost $65 \%$ of the respondents indicated that they felt others viewed them as professionals.

Inferential statistics were calculated to examine any variances in perceptions of professionalism among the participants. A Kruskal-Wallis test of one-way variance determined a variance in perceptions of professionalism based on the five levels of experience (less than 5 years, 6 to 10 years, 11 to 15 years, 16 to 20 years, and more than 21 years) and four levels of education (college diploma, university degree with and without a bachelor of education, and graduate degree). Specifically, educators with less than 5 years of experience perceived that others were less likely to view them as a professional, while educators with more than 21 years of experience felt strongly that others viewed them as professionals $(\chi 2(4)=10.303, p=0.036)$. Moreover, educators with a bachelor's degree reported feeling strongly supported in their role in comparison to educators with a college diploma or a master's degree, who did not report feeling as strongly supported in their role $(\chi 2(3)=11.185, \mathrm{p}=0.11)$. Thus, although the participants overwhelmingly reported a strong sense of professionalism, there were subtle differences in those perceptions that were also explored through a qualitative lens.

\section{Qualitative Conceptions of Professionalism}

In this study, the participating educators reported a strong sense of perceived professionalism, yet both autonomy and collegiality were mediating influences that acted to limit professionalism (see later discussion on mediating influences). To better understand the meanings of the educators' perceptions of professionalism (Dalli, 2008) and how these perceptions would be described qualitatively, the participants were asked to (a) list the qualities they would expect to find in an early years educator that they would describe as a professional and (b) describe how they would recognize professionalism in early years educators' interactions across a range of workplace situations.

The most frequently used descriptors utilized by the participants in their conceptualization of the qualities of a professional included caring, knowledgeable, selflearner, and respectful. Caring was one of the most frequently reported qualities of a professional. The concept of caring included references the participants made to compassion, patient, loving, kindness, and ethics. Participant 16 noted that professionalism is a delicate balance and is evidenced by an individual who "maintains an appropriate boundary between being caring and being ethical." 
According to Brock (2012), an educator's role is multifaceted and "involves understanding teaching methodologies, developing curriculum frameworks and organizing children's learning experiences" (p. 38). The 37 study participants appeared to recognize the distinct levels of knowledge required of their roles and referred to the importance of having an understanding of how children learn, of learning/developmental theories, and of early child development. Being knowledgeable as a professional tended to be an all-encompassing construct, as Participant 5 noted in her comments:

\section{[A professional] advocates for the needs of children, communicates and} understands child development, understands and applies current research/evidence, [applies] observation-informed practise, attends professional development opportunities.

Additionally, based on the participants' responses, we used the theme "selflearner" to refer to educators' conceptualizations of qualities of professionalism that included being inquisitive, a lifelong learner, reflective, intuitive, and able to apply acquired knowledge.

The theme of respect was also evident in the participants' responses. Here, educators referred to qualities such as being observant, inclusive, respectful of diverse cultures, and having a non-judgmental view of the children and others. Participants appeared to consider respect as a quality of a being professional, an inherent disposition of the individual. Respect also appeared as a theme related to educators' interactions.

In terms of recognizing professionalism in early years educators' interactions across a range of workplace situations, the participants most frequently reported on the role of respect, a strong work ethic, educator development, and professionalism in practice. In terms of respect and professional interactions, the educators discussed concepts such as acting responsibly toward children, parents, and other colleagues, being supportive of one another's roles, maintaining a collaborative orientation, demonstrating a willingness to share resources, upholding confidentiality, and "being a team player" (Participant 20).

The theme "work ethic" included responses related to acting ethically, being nonjudgmental, maintaining an appropriate attire and comportment, and demonstrating commitment to one's role. For example, in terms of the latter, Participant 21 referred to "a person who is not concerned about financial gain and can work 15 minutes before or after school even if they are not being paid."

Professionalism in practice tended to include descriptions related to ideas of "best practice," demonstrating desires and behaviours to improve practice, and use of observation and research-informed practices. For example, Participant 37 described her 
ability to recognize professionalism in others as reflective of "an individual who can articulate the "why' behind what they are doing regardless of the situation."

\section{Mediating Influences on Early Years Educators}

In 2010, Ontario began implementing full-day early learning within the formal education system under the jurisdiction of the Ministry of Education. Perhaps Ontario is mirroring the international developments of integrated publicly funded delivery systems in other nations. For example, France, Italy, Belgium, Austria, Germany, New Zealand, Spain, Slovenia, England, Scotland, Brazil, Iceland, Norway, and Sweden deliver care and education programs for preschool children in seamless models (Bennett, 2008). Regardless, the shift in jurisdiction and oversight of the ECE sector from the Ministry of Children and Youth Services to the Ministry of Education serves as a potential first step for the integration of early years services in Ontario. Several changes occurred as a result of the shift, ultimately impacting legislation, policy, funding, quality assurance procedures, and structural changes within the education ministry itself. In light of these developments, to better understand the potential role of the socio-political landscape on perceptions of professionalism, the study participants were asked to discuss obstacles and challenges they had experienced in association with professionalism and professional identity construction. If they were part of an ELKP team, they were asked to describe any experiences with opportunities for and challenges to professionalism and professional development. Fourteen of the participants (4 teachers and 10 RECEs) were part of an ELKP team, and the majority of them indicated that it was their second year in an ELKP classroom.

Four themes emerged from the participants' qualitative responses: (a) internal perceptions that devalue the role of an early years educator; (b) external perceptions that devalue the role of an early years educator; (c) compatibility of the relationship between early childhood educators and teachers; and (d) levels of education and years of service. Below we discuss each of these themes individually; however, it is important to consider how these four constructs are interrelated and interdependent. Potentially, this interrelation and interdependence of constructs may have a greater impact on fuelling the glass ceiling effect on professionalism and professional identity construction than the presence of any one construct alone. Nevertheless, much like the transparent glass ceiling itself, the "invisible" barriers that study participants discussed appeared to negatively impact their sense of professionalism.

\section{Internal Perceptions that Devalue an Early Years Educator}

We categorized participants' discussions of the lack of professional development opportunities and the negative views of administrators, teachers, and staff as internal perceptions that devalue early years educators. In terms of identified challenges, participants branded principals', teachers', and other administrative staff persons' 
commonly held perceptions of their role of an early years educator as an obstacle to professionalism and professional identity construction. Often these commonly held perceptions were critiqued by the participants as part of the rationale for the devaluing and lack of supports for early years programs within the education sector itself. As Participant 16 expressed, "school boards until recently always thought of us as 'babysitters' not 'educators' [and although] that is now changing, [it] can still be readily seen in some schools/situations." Lack of adequate resourcing for early years programming appeared to be aligned with participants' sense of devaluation. Participant 19 shared that 'kindergarten is [considered] a 'program,' not a mandated curriculum; therefore, the support for high needs students [is] not available." Leadership was also highlighted as an obstacle: "a principal and vice-principal who don't know the kindergarten curriculum; a principal who doesn't understand multiple intelligence; a principal and vice-principal who don't understand the developmental continuum" (Participant 25). The qualitative discussion of perceived respect was mirrored in the quantitative findings. Here, the roles of administrators, teachers, and staff were predictive of educators' perceptions of how they felt supported in their role $(\beta=0.819, p=0.000)$. Similarly, the perceived level of support by others was predictive of the participants' professed feelings of being respected in their position $(\beta=0.457, p=0.000)$.

Another devaluing mechanism the participants expressed was related to professional development (PD) and opportunities for professional growth. Participants noted obstacles such as "few opportunities for paid and ongoing PD" (Participant 37) and "very rarely is professional development offered with our teaching partners" (Participant 22). Limited diversity in the professional development opportunities was also noted as a challenge to professional growth. For example, Participant 24 stated: "we have had workshops for us after school but when it comes to PD day stuff it's the same stuff over and over and there are no new opportunities to learn new things."

\section{External Perceptions that Devalue an Early Years Educator}

The participating educators also identified perceptions of parents and the general public regarding the value of early years educators as an obstacle to professionalism and constructing a professional identity. Congruent with the descriptions of internal stakeholders' perceptions within the education system, one educator stated:

The average person's perception in Canada is that working with children 0-6 years old is babysitting. There is now a small shift in the understanding that the early years are the foundation of the child's health and well-being. More knowledge on the importance of the early years needs to be communicated to the public. This understanding would help [the] government provide funds for the programs that are needed in every community for this age group. (Participant 1)

\section{Canadian Children}


Another educator concurred, explaining that a challenge to professionalism was related to "societal misunderstanding of the role of ECEs, [misunderstandings of] the importance of the early years and brain development, and a general lack of ECEs' ability to communicate with parents and the community about what they do" (Participant 5). In addition, it was clear in the findings that the perceptions of parents and the public are predictive of educators' perceptions and understanding of the responsibilities of their role $(\beta=0.244, p=0.045)$.

\section{Compatibility of the Relationship}

A notable recurring theme in the participants' narrated responses was the compatibility of the relationship between early childhood educators and teachers. The educators identified the relationship compatibility of the RECE and teacher as both an opportunity and a challenge associated with professionalism and constructing a professional identity. One educator highlighted this complexity by stating:

[I am] amazed at the constant opportunities for growth and learning. I always come away with new knowledge that I'd love to apply, but as an ECE I am then met with the larger challenge of trying to convince my teaching partner to move forward. We as ECEs can only be as good as we are permitted to be as it seem to be up to the teacher to have the final say and decide how the program will unfold. (Participant 23)

The compatibility of the relationship was also described as a journey:

As a DECE [designated ECE] within the school board I have had the opportunity to get back to what I went to school for, which was helping children learn and adjust to the world around them. The school board has given me the opportunities to make the time that I spend with children meaningful and measurable. As a DECE it has been a journey with my teaching partner to navigate our roles, responsibilities, and strengths. I feel that I have had to prove to her that I am as much of a professional as she is. I feel great now that she feels confident in my abilities as her teaching partner and not her assistant. (Participant 26)

One educator shared the importance of establishing this balance and compatible relationship as an opportunity for professional growth:

Developing a relationship with your partner is an important part of the early learning team. Having difficult conversations and challenging each other's practices is very important, yet challenging. The beautiful part of the partnership is how much the roles complement each other. I have 
learned so much from my ECE partners about documentation, child development, assessment, and play. (Participant 31)

The participants also noted obstacles that challenge the compatibility of this relationship. Most notably, these obstacles include the pay differential that exists between educators and teachers, contrary belief systems, ill-defined roles, lack of shared professional development opportunities, and the need for "joint planning/prep time offered for RECEs with their teaching partners" (Participant 22).

\section{Level of Education and the Years of Service}

The participating educators identified level of education and years of service as obstacles associated with professionalism and constructing a professional identity. One educator shared that a lack of value and recognition exists in relation to a college diploma (the minimal requirement for an RECE).

Recognition as an educator in the childcare setting is challenging. [Specifically], [there is] less recognition of a college diploma [than a] university degree. Intense training in child development is more credible than a degree in geography. When is the educational field going to recognize that social and emotional growth is just as important as learning academics? (Participant 8)

Another educator shared the trials associated with pay and professional identity, saying, "if pay does not reflect our responsibilities in comparison to our teaching partner then we will never be viewed as a professional" (Participant 23).

These responses are congruent with the perceptions of professionalism that educators shared in respect to specific level of education and years of service. Educators with a bachelor's degree reported a stronger belief that they were supported in their role compared to educators with college diplomas or master's degrees $(\chi 2(3)=11.185, \mathrm{p}=$ 0.011 ). Also, feeling qualified and confident to help others learn about the role of early years educators was predictive of enjoyment of work $(\beta=0.915, p=0.005)$. Educators with more than 21 years of experience reported more robust perceptions that others were likely to view them as professional compared to educators with 20 years experience or less $(\chi 2(4)=10.303, p=0.036)$. The educational training requirements between the two sectors appeared to impact perceptions of professionalism. Participant 21 said:

I wonder if the ECE see themselves as teachers, if the public sees them as a teacher, and if society sees them as teachers. With only two years of further education should they be considered in the same light [as professionals] just like a teacher who holds a degree and also a bachelor of education degree? I think that the term 'professional' is usually 
reserved for doctors, lawyers, teachers (someone with advanced

education).

\section{Summary and Discussion}

The goal of this small-scale study of educator insights and beliefs related to perceived qualities of professionalism and the potential mediating factors that may influence professional identity construction was to gain a beginning understanding of concepts of professionalism within and between the two historically divided sectors of education and care. Professionalism is a challenging construct to define (Evetts, 2009). An educator's role is complex, involving specific "knowledge domains, beliefs and practices, [and ability to demonstrate] the interplay between personal voices and professional ideologies" (Brock, 2012, p. 27). Perhaps the typology of interrelated dimensions of professionalism proposed by Brock can inform the discourse within Ontario. In Brock's (2012) research in the United Kingdom, she too utilized educators' voices to define seven interrelated aspects of professionalism: (a) knowledge, (b) qualifications, training and professional development, (c) skills, (d) autonomy, (e) values, (f) ethics, and (g) rewards (p. 27).

Yet opportunities to engage in critical and analytical discourse on professionalism appear to be largely absent in the Ontario context, and reconceptualist discussions "remain outside the Canadian ECEC mainstream" (Pacini-Ketchabaw \& Pence, 2005, p. 13). Spaces for educators themselves to reflect, critique, and evaluate their role may be a key aspect of pursuing and defining professionalism and countering deprofessional discourses (Hargreaves, 2000; Hughes \& Menmuir, 2002). As the Ontario early years landscape shifts, opportunities to reimagine early years professionalism through research seem fundamental (Woodrow, 2007).

The 37 educators in this study reported high levels of professionalism, and they conceived of professionalism as encompassing dimensions of caring, knowledge, selflearning, and respect. Additionally, the educators noted the roles of respect, work ethic, educator development, and professionalism in practice as integral in educators' professional interactions. Like Brock (2012), the educators who participated in this study highlight the complexity of defining and recognizing professionalism, providing valuable insights into constructing a holistic view of early years professionalism within the Ontario context.

The participants also noted specific internal and external influences that impact professionalism and professional identity construction. Specifically, educators noted that they felt devalued by the lack of understanding from administrators and principals, and they attributed the deficiency of resourcing and professional supports as reflective of this devaluing. As Stamopoulos (2012) suggests in her leadership model, principals, along with postsecondary institutions and professional organizations, have a direct role to play 
in building professional competency of educators. However, the idea of "reframing early childhood leadership from a shared responsibility" lens (Stamopoulos, 2012) was not evident in the professionalism discourse of the educators who participated in this study, nor does the concept appear evident in the Ontario education policy context.

Moreover, the findings from this study provide insight into how notions of professionalism are impacted by the external environment. Here, educators noted the role of parents and society in shaping the professionalism discourse. Thus, in keeping with Dalli and her colleagues' notion of the "critical ecology of the early childhood profession," the conceptualization of professionalism needs to be considered within "the complex realities in which early childhood practitioners live their lives and their profession, and how practitioners' realities are inextricably linked to their wider context" (Dalli et al., 2012, p. 7).

Interestingly, the participants noted that the compatibility of the relationship between early childhood educators and teachers was both an opportunity and a challenge to professionalism. Purposefully planned opportunities for all early years educators to generate and find new ways of being in relationship with one another appear to be a foundational piece to the discussion of professionalism within the Ontario early years sector. Currently, the training and education of early years educators is fragmented, with early childhood educators requiring a two-year college diploma and teachers a bachelor's degree and certification (typically a four-year university degree coupled with a one-year university certification). Some countries (e.g., Sweden, Denmark, and Finland) have integrated a coherent approach in training all educators who work with young children (Oberhuemer, 2005). And although the Ontario Early Years Policy Framework (Ontario Ministry of Education, 2013) identifies priority areas to foster system and policy integration within the province, noticeably absent is any reference to professionalism, dimensions of professionalism, leadership, and training.

\section{Conclusion}

The findings of this small-scale study offer some beginning insights into educators' thoughts and conceptions of professionalism. We hope to foster greater discourse and critique of professionalism in Ontario and beyond. From a critical ecology of the early childhood profession perspective, educators, leaders, policy makers, and educational systems need to consider new models of training and pathways for the coconstruction of professional identities for all early years educators. An integrated training model for all educators and teachers who work with children from birth to 8 years of age (i.e., the foundational stages of development and early learning) could foster greater opportunities for developing a common knowledge and understanding of the continuum of children's learning and developmental needs. In France, all educators working with young children 2 to 11 years of age receive the same training and job title: professeur des 
écoles (New \& Cochran, 2007). A shared training experience and a common foundation of knowledge could foster opportunities for the co-construction of a professional identity for all early years educators, ultimately strengthening educators' ability to define and enhance their sense of professionalism and capabilities in countering any deprofessionalism rhetoric and initiatives.

We suggest that the current environment in Ontario fosters a glass ceiling effect for professionalism and professional identity construction (i.e., perceived differences of professionalism) that may inadvertently add to the fragmentation and marginalization of the early years sector. Throughout this article, we used the glass ceiling metaphor to explore some of the structural and attitudinal barriers that exist within the current early years sector of care and education in Ontario. Similar to existing research, the glass ceiling effect we discuss describes inequalities or differences that were identified by the participating educators and that operated to negatively impact professionalism (Cotter et al., 2001). Thirty-seven educators shared their insights on the role of several constructs that impact one's sense of professionalism. Some of these constructs, such as pay and education differentials, administrative leadership and lack of understanding, and societal misunderstandings can act as barriers to professionalism. However, the authors note that any of these constructs that were conceptualized as constraints can be reimagined as opportunities. One has only to visualize a glass ceiling made of Venetian Murano glass to imagine the endless possibilities, patterns, and pathways of professionalism that can be fostered. Venetian Murano glass is revered worldwide for its mastery, brilliance, and uniqueness (Heiremans, 2002). The making of the glass relies on a team of master craftspersons who couple centuries-old techniques with contemporary practices (Bentham, 2006; Levin, 2004). Reimagining the glass ceiling of professionalism through a Murano glass lens can help foster a discourse that explores possibilities and opportunities for redefining professionalism within the early years sector. A coherent and integrated training model and professional development training for all those working within the early years sector is an example of this reimagining.

\section{References}

Bennett, J. (2008). Early childhood education and care systems in the OECD countries: The issue of tradition and governance. In R. E. Tremblay, R. G. Barr, R. DeV. Peters, \& M. Boivin (Eds.), Encyclopedia on early childhood development. Retrieved from: http://www.child-encyclopedia.com/

Bentham, D. (2006). The island of blown glass. Glass Age, 49(7), 18-18.

Brock, A. (2012). Building a model of early years professionalism from practitioners' perspectives. Journal of Early Childhood Research, 11(1), 27-44. doi:

$10.1177 / 1476718 \times 12456003$ 
Cherrington, S., \& Thornton, K. (2013). Continuing professional development in early childhood education in New Zealand. Early Years: Journal of International Research \& Development, 33(2), 119-132.

College of Early Childhood Educators. (2013). Purpose and mandate. Retrieved from: http://www.college-ece.ca/en/AboutUs/Pages/Purpose-and-Mandate.aspx

Cotter, D. A., Hermsen, J. M., Ovadia, S., \& Vanneman, R. (2001). The glass ceiling effect. Social Forces, 80(2), 655-682.

Creswell, J. W. (2012). Educational research: Planning, conducting, and evaluating quantitative and qualitative research $\left(4^{\text {th }}\right.$ ed.). Boston, MA: Pearson Education.

Dalli, C. (1993). Is Cinderella back among the cinders? A review of early childhood education in the early 1990s. New Zealand Annual Review of Education, 3, 223252.

Dalli, C. (2008). Pedagogy, knowledge and collaboration: Towards a ground-up perspective on professionalism. European Early Childhood Education Research Journal, 16(2), 171-185.

Dalli, C., Miller, L., \& Urban, M. (2012). Early childhood grows up: Towards a critical ecology of the profession. In L. Miller, C. Dalli, \& M. Urban (Eds.), Early childhood grows up: International perspectives on early childhood education and development (pp. 3-19). London, UK: Springer.

Evetts, J. (2009). New professionalism and new public management: Changes, continuities, and consequences. Comparative Sociology, 8(2), 247-266.

Government of Ontario. (1990). Day Nurseries Act, R.R.O. 1990, Regulation 262 Stat.

Hargreaves, A. (2000). Four ages of professionalism and professional learning. Teachers and Teaching: Theory and Practice, 6(2), 151-182.

Heiremans, M. (2002). Murano glass: Themes and variations. Stuttgart, Germany: Arnoldsche.

Hughes, A., \& Menmuir, J. (2002). Being a student on a part-time early years degree. Early Years, 22, 147-161.

Katz, L. G. (1972). Developmental stages of preschool teachers. Elementary School Journal, 73, 50-54.

Katz, L. G. (1985). The nature of professions: Where is early childhood education? Paper presented at the Early Childhood Organisation Conference, Bristol Polytechnic, Bristol, UK. 
Lee, I. F. (2012). Unpacking neoliberal policies: Interrupting the global and local production. Journal of Pedagogy, 3(1), 30-42. doi: 10.2478/v10159-012-0002-z

Levin, B. (2004). Murano glass factory. Stained Glass: Quarterly of the Stained Glass Association of America, 99(4), 300-303.

Martin, S., Meyer, J., Jones, R. C., Nelson, L., \& Ling, T. (2010). Perceptions of professionalism among individuals in the child care field. Child \& Youth Care Forum, 39(5), 341-349.

Miller, L., \& Cable, C. (2011). The changing face of professionalism in the early years. In L. Miller \& C. Cable (Eds.), Professionalism, leadership and management in the early years (pp. 1-10). London, UK: SAGE.

Moss, P. (2013). The relationship between early childhood and compulsory education: A properly political question. In P. Moss (Ed.), Early childhood and compulsory education: Reconceptualising the relationship (pp. 2-49). Milton Park, UK: Routledge.

New, R. S., \& Cochran, M. (2007). Early childhood education: The countries. Westport, CT: Greenwood.

Oberhuemer, P. (2005). Conceptualising the early childhood pedagogue: Policy approaches and issues of professionalism. European Early Childhood Education Research Journal, 13(1), 5-2. doi: 10.1080/13502930585209521

Ontario College of Teachers. (2013). About the college. Retrieved from: $\mathrm{http}: / /$ www.oct.ca/about-the-college

Ontario Ministry of Education. (2010). The full-day early learning-kindergarten program. Draft version. Retrieved from: http://www.edu.gov.on.ca/eng/curriculum/elementary/kindergarten_english_june3 .pdf

Ontario Ministry of Education. (2013). Ontario early years policy framework. Toronto, ON: Queen's Printer.

Opper, S. (1993). Kindergarten education: Cinderella of the Hong Kong education system. In A. B. M. Tsui \& I. Johnson (Eds.), Teacher education and development (Vol. 18, pp. 80-89). Hong Kong: University of Hong Kong.

Organisation for Economic Cooperation and Development. (2001). Starting strong: Early childhood education and care. Paris, FR: Author.

Organisation for Economic Cooperation and Development. (2006). Starting strong II: Early childhood education and care. Paris, FR: Author. 
Oxford University Press. (2014). Professionalism. Retrieved from: http://www.oxforddictionaries.com/definition/english/professional

Pacini-Ketchabaw, V., \& Pence, A. (2005). Contextualizing the reconceptualist movement in Canadian early childhood education. In Pacini-Ketchabaw \& A. Pence (Eds.), Early childhood education in motion: The reconceptualist movement in Canada (pp. 5-20). Ottawa, ON: Canadian Child Care Federation.

Rodgers, C. R., \& Raider-Roth, M. B. (2006). Presence in teaching. Teachers and Teaching: Theory and Practice, 12(3), 265-287.

Stamopoulos, E. (2012). Reframing early childhood leadership. Australasian Journal of Early Childhood, 37(2), 42-48.

Woodrow, C. (2007). Whither the early childhood teacher: Tensions for early childhood professional identity between the policy landscape and the politics of teacher regulation. Contemporary Issues in Early

${ }^{\mathrm{i}}$ Ages vary by country. 


\section{In this issue:}

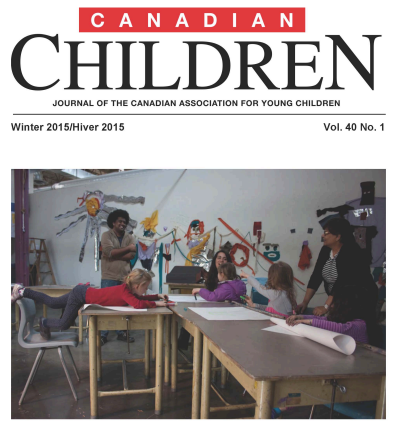

From the Editors' Desk Special Issue: Professionalism in ECEC Guest Editors: Dr. Rachel Langford, Dr. Jane Hewes, Sonya Hooper, and Monica Lysack

Beyond Professionalism: Interrogating the Idea and the Ideals by Randa Khattar and Karyn Callaghan

Negotiating Status: The Impact of Union Contracts on the Professional Role of RECEs in Ontario's Full-Day Kindergarten Program by Romona Gananatham

The Glass Ceiling Effect: Mediating Influences on Early Years Educators' Sense of Professionalism by Stefanie Tukonic and Debra Harwood

Enhancing Professionalism and Quality Through Director Training and Collegial Mentoring by Glory Ressler, Gillian Doherty, Tammy McCormick Ferguson, and Jonathan Lomotey

Authoring Professional Identities: Immigrant and Refugee Women's Experiences in an Early Childhood Teacher Education Program by Christine Massing

ECEs as Childcare Advocates: Examining the Scope of Childcare Advocacy Carried out by ECEs from the Perspective of Childcare Movement Actors in Ontario and Manitoba by Lyndsay Macdonald, Brooke Richardson, and Rachel Langford

From Child-Minders to Professionals: Insights From an Action Research Project on Prince Edward Island by Anna Baldacchino, Ray Doiron, Martha Gabriel, Alaina Roach O'Keefe, and Jessica McKenna

Pedagogical Narrations and Leadership in Early Childhood Education as Thinking in Moments of Not Knowing by Iris Berger

Find other articles from this issue at www.cayc.ca 